Journal of

Child Health Care

\title{
Exploring participation after paediatric acquired brain injury
}

\begin{tabular}{|c|l|}
\hline Journal: & Journal of Child Health Care \\
\hline Manuscript ID & JCHC-2018-0337.R4 \\
\hline Manuscript Type: & Original Article \\
\hline Keyword: & Children and Young People, Acquired Brain Injury, Participation \\
\hline Abstract: & $\begin{array}{l}\text { This study aimed to explore the levels of participation in a UK sample of } \\
\text { children and young people (CYP) with an acquired brain injury (ABI) at } \\
\text { home, school and in the community. The purpose of this study was to } \\
\text { assess the feasibility of undertaking research with this population with a } \\
\text { cross-sectional study using the Child and Family Follow-Up Survey } \\
\text { (CFFS). The CFFS was distributed to parents/carers of } 134 \text { CYP with ABI } \\
\text { (CYP-ABI) who received neuro-rehabilitation from 2014 to 2016. Access } \\
\text { and recruitment was problematic resulting in a low response rate (4\%). } \\
\text { Widespread restrictions in participation were reported by } 4 \text { out of the } 5 \\
\text { respondents with community structured events/activities and educational } \\
\text { activities being the most restricted. Factors impacting on participation } \\
\text { were cognitive-based and movement skills, family stress and lack of } \\
\text { support/encouragement in the community. Study results provide } \\
\text { information pertaining to the feasibility of undertaking research with this } \\
\text { population whilst also highlighting the restrictions to participation } \\
\text { experienced by CYP-ABI more than two years after injury. }\end{array}$ \\
\hline
\end{tabular}

\section{SCHOLARONE" \\ Manuscripts}




\title{
Exploring participation after paediatric acquired brain injury
}

\begin{abstract}
$\underline{\text { Abstract }}$
This study aimed to explore the levels of participation in a UK sample of children and young people (CYP) with an acquired brain injury (ABI) at home, school and in the community through a cross-sectional study. The Child and Family Follow-Up Survey (CFFS) was distributed to parents/carers of $134 \mathrm{CYP}$ with $\mathrm{ABI}$ (CYP-ABI) who received neurorehabilitation from 2014 to 2016 . Access and recruitment was problematic resulting in a low response rate $(4 \%)$. Widespread restrictions in participation were reported by 4 out of the 5 respondents with community structured events/activities and educational activities being the most restricted. Factors impacting on participation were cognitive-based and movement skills, family stress and lack of support/encouragement in the community. Study results provide information pertaining to the feasibility of undertaking research with this population whilst also highlighting the restrictions to participation experienced by CYP-ABI more than two years after injury.
\end{abstract}

\section{Keywords}

Children and young people, acquired brain injury, participation 


\section{$\underline{\text { Introduction }}$}

Whilst global prevalence is unclear, annually in the UK an estimated 40,000 children and young people (CYP) sustain an acquired brain injury (ABI) (NHS England, 2013). A childhood ABI can lead to a complex array of physical, cognitive, social, emotional and behavioural impairments which can result in lifelong disability (Andersson et al., 2016; Gordon and Di Maggio, 2012; Popernack et al, 2015). The long-term impact of these impairments on a CYPs physical and psychological development, quality of life (QoL), educational achievement and social inclusion can be significant, but often difficult to predict and monitor (Anderson et al., 2006; Anderson et al., 2012; Bedell and Dumas, 2004; Galvin et al., 2010; Kirk et al., 2015; Limond et al., 2009; Manning et al., 2017). Many factors influence recovery including site/size of the lesion, age at injury, premorbid abilities, family functioning, personal and environmental factors and variability in rehabilitation service provision (Galvin et al., 2010; Gordon and Di Maggio, 2012). The consequences of an ABI may continue to become evident months or years after the event as developmental, education and social demands increase and are often underrecognised and misunderstood (Feary and McKinlay, 2018; Gordon and Di Maggio, 2012).

Evaluating the effectiveness of rehabilitation is essential to expand the evidence base to inform commissioning and service development decisions in today's healthcare economic climate (Datta and Petticrew, 2013). Although researchers and clinicians agree that a multi-faceted approach is required, to date, there is no standardised formula or consensus on how to measure CYP-ABI outcomes effectively. The Royal College of Paediatrics and Child Health (RCPCH) childhood stroke guidelines recommend multi-disciplinary assessment of CYP and family needs using the World Health Organisation's (WHO) International Classification of Functioning, Disability and Health (ICF) domains and QoL measures, however no specific outcome measures are recommended (RCPCH, 2017; WHO, 2002). Consequently, identification of influential factors for recovery is limited, impacting development of the 
evidence base for interventions (Badge et al., 2009; Gordon, 2014). Badge et al. (2009) through literature review and extensive Australian clinical consultation identified three main rehabilitation outcome priorities: family functioning, school performance and participation.

The ICF, a holistic biopsychosocial model for describing and understanding the impact of a health condition on a person, defines participation as 'involvement in a life situation' (WHO, 2002). Participation is an essential part of child development, associated with increased QoL, social competence and educational success of CYP with and without disabilities (Bedell et al., 2011; Galvin et al., 2010; WHO, 2002). Whilst there is some development of the literature field regarding participation of children with disabilities such as cerebral palsy, the field of literature for CYP-ABI is as yet under-developed. Participation has been found to be restricted in CYP-ABI in several studies in the USA, Canada and Australia (De Kloet et al., 2015; Fougeyrollas et al., 2014; Law et al., 2011; Thompson et al., 2016). However, no such studies researching participation in UK CYP-ABI were identified. Further research is required to explore measurement tools, data collection methods and this population's response to participation in research. Such work may contribute to conceptualising participation after paediatric $\mathrm{ABI}$ and inform larger scale studies.

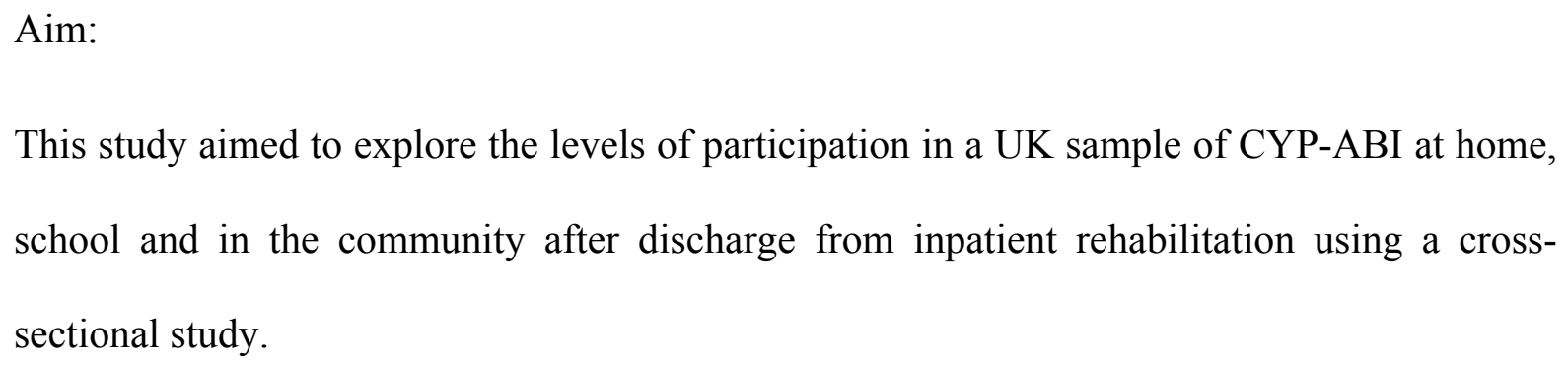
school and in the community after discharge from inpatient rehabilitation using a crosssectional study.

\section{$\underline{\text { Method }}$}

Participants and procedures: 
A cross-sectional survey was identified as an appropriate method, to access information from a larger target population (Bowling, 2014). The methodological and procedural components; the recruitment processes and procedures and appropriateness of the selected outcome measure (CFFS) were also evaluated (Arain et al., 2010).

A purposive sampling strategy was used to recruit participants from four centres in England. Local collaborators identified eligible participants from existing service user databases using pre-determined eligibility criteria (stated below). Postal invitation letters and participant information sheets, specific for parents/carers and for CYP, were sent, inviting participants to access and complete the online survey. Further telephone reminders were completed by the local collaborators four weeks after the postal invitations were sent.

Inclusion criteria:

- Parents/carers of CYP-ABI aged 5-18 who received inpatient neurorehabilitation at one of the identified four centres between October 2014 and October 2016

- Sufficient command of the English language to understand the study literature, consent and complete the survey

- CYP aged 11-18 associated to the participating parent/carer who consented to complete the CYP section of the survey.

Exclusion criteria:

- Parents/carers of CYP under 5 or over 18 (outcome measure requirements)

- Insufficient command of English language to complete the survey

- Parents/carers and CYP unable to provide assent or consent to participation.

- CYP under age of 11 years (outcome measure requirement) 
Ethics:

Ethical and governance approvals were gained from National Research Ethics Committee and four participating National Health Service sites (REF: 17/WM/0163). Vital to any clinical ethical approval is that all principles of ethical research have been met (Emanuel, Wendler and Grady, 2000). In this research study practical examples include compliance with the General Data Protection Regulations 2018, data confidentiality and protection and risk benefit equipoise. The research team carefully considered the online survey approach's potential to allow frank and honest responses whilst recognising the need for parental guidance where a child completed their sections, given the potential sensitive nature of the issues being explored. Participants were provided with contact details for the research team and their local clinicians should any concerns arise.

Survey:

Bristol Online Survey (BOS) was used to create an online survey using demographic questions, consent and the CFFS. Permission was given by the CFFS's author (Professor Gary Bedell, $\mathrm{PhD}$ ) for this and some minor alterations to the wording (American to English) for local context and UK spelling. Content and face validity were reviewed by the research team.

A review of the literature and the participation outcomes used in previous studies (Chien et al., 2014; De Kloet et al., 2015) identified the CFFS as an appropriate outcome measure for this feasibility work. Originally developed to monitor outcomes and needs of CYP-ABI, the CFFS was developed from the ICF and quantitative and qualitative research regarding participation of CYP with a range of disabilities (Bedell, 2011). The CFFS is a parent-reported standardised measure, validated in North America and Australia, with good test-retest reliability (0.67-0.94), 
internal consistency (0.91-0.98) and evidence of criterion-validity (Galvin et al., 2010). Normative data is not currently available, but results can be descriptively interpreted to understand patterns of participation (Galvin et al., 2010; McDougall et al., 2013). Included within the CFFS are three quantitative scales; the Child and Adolescent Scale of Participation (CASP), Child and Adolescent Factors Inventory (CAFI) and Child and Adolescent Scale of Environment (CASE), and open-ended questions giving opportunity for further information to be shared.

CASP: Participation levels of CYP-ABI in activities at home, school and the community are scored for 20 items using a Likert scale (1-4) or not applicable. Item scores are added together and divided by the maximum score for each applicable item giving a total score ranging from 0-100. Higher scores indicate CYP are participating at age expected levels. Parent and CYP aged $11+$ versions are available and important to ensure both perspectives are captured (McDougall et al., 2013). The CASP-Youth version (CASP-Y), has been validated in Canadian English speaking 11-17 year olds (McDougall et al., 2013). It is considered a reliable and valid measure as strong internal structure validity and internal consistency (Cronbach's $\alpha=0.87$ (youth) and 0.95 (parent)) is reported for both versions and intra-class correlation moderate agreement $(\mathrm{ICC}=0.63,95 \%$ confidence interval $=0.41-0.75$ ) between the two versions (Adolfsson et al., 2011; Bedell and Coster, 2008; Chien et al., 2014; McConachie et al., 2006). CAFI: Parent-reported scale that measures the impact of child-related impairment factors on participation across 15 items.

CASE: Parent-reported scale that assesses environmental factors as facilitating or hindering participation across 18 items.

Both the CAFI and CASE are scored on a scale of 1-3 or not applicable, total scores can be calculated for each measure, higher scores indicating significant impairment or environmental problems impacting on participation. 
Data Analysis:

Completed survey results were downloaded from BOS and reviewed in Microsoft Excel format. Participants completed the survey anonymously, however, where names were mentioned in the free text boxes these were anonymised. STATA (Version 15, 2015) was used to analyse quantitative data. Descriptive analysis was conducted for the demographic information, CASP, CASP-Y, CAFI and CASE data.

The responses to open-ended question were analysed using the thematic analytical approach by Braun and Clarke (2006). This data driven approach allowed for emergent themes to be identified through a process of (1) reading for familiarity; (2) line-by-line coding; and (3) reading, connecting and aggregating the code into themes (emergent) (Maguire \& Delahunt 2017).

\section{$\underline{\text { Results }}$}

Respondents:

In total 134 (centre $1 n=60$; centre $2 n=17$; centre $3 n=17$; centre $4=40$ ) invitations were sent. Only five responses were received giving a response rate of $4 \%$. All five parent respondents were mothers. Three of the participants were over 11 years old and all three consented to complete the CASP-Y. The characteristics of the participants are displayed in Table 1. 
[Insert Table 1]

\section{Participation (CASP/CASP-Y):}

Parent-reported total scores ranged from 70-100 (median=82.50). Age appropriate participation in all items was reported for one CYP, however restrictions in 19/20 items were reported for four CYP (Table 3). Structured events/activities and educational activities were the most restricted ( $\mathrm{n}=4$ somewhat or very restricted). Further restrictions were reported in communication, social, play, and leisure activities with friends, moving around neighbourhood, household activities and using transport.

Three CYP completed the CASP-Y, with one CYP reporting no participation restrictions. Two CYP participants reported restrictions in 18/20 items (Table 2). Whilst there was general agreement in the restricted items between parents and CYP, there were differences in terms of degree of restriction. One CYP's total score being higher than the parent's score $(83.82 \mathrm{v}$ 71.05), and the other CYP's score lower (66.25 v 70.00).

[Insert Table 2]

Child-related difficulties (CAFI):

One CYP had no parent-reported problems in any areas. Significant impairments were reported by four parents with total scores ranging from 44.44-71.11. Cognitive based skills, behaviour management, movement, strength and energy levels, speech and sensory problems were the highest reported impairments with only hearing reported as unaffected by all. 
Environmental difficulties (CASE):

Environmental barriers were reported for four out of five participants. Family stress, lack of support/encouragement and services in the community were reported as barriers to participation.

Open-ended questions findings:

Four out of five participants responded to the open-ended questions with 14 different codes being identified. Two main themes emerged: cognition and communication difficulties and environmental factors. The later included barriers and facilitators to participation and CYP, parental and school responsiveness to adaptation.

Participation restrictions due to communication difficulties were reported in the measurable and open-ended questions by the CYP respondents and their parents, indicating a significant problem for both. One CYP stated 'My speech gets in the way a bit but I try and talk to my friends and they always listen and now I've started talking again me and my friends are getting along much better' whilst another stated 'Seizures as they make me tired, fatigue, concentration. I sometimes struggle to communicate what I want to say, no word finding'.

Parents and CYP reported strategies used to support and improve participation, particularly at school. Open-ended responses demonstrated families' reliance upon school responsiveness to adapt for the child's altered needs post ABI and implement support strategies. These included teaching assistant support, altered timetables and working environments. One parent reported 'We try to keep [her] in a more quiet environment at school, she works in small groups rather than a full class, she has regular 'brain breaks', she has a chill out area to go when feeling frustrated'.

Parents were also asked about other services, assistance and information they felt they needed to support participation. Parents identified a lack of emotional and peer support for the CYP- 
ABI, siblings and parents as a barrier, three providing detailed responses about how they felt they, their CYP and family needed help to learn to accept, develop coping strategies and discuss problems that arise. One parent stated 'support and coping strategies, support groups. Offer support to families to help them learn to accept and cope including siblings once discharged [home]. We were offered nothing and have struggled daily with the stresses'.

\section{Discussion:}

Participation is vital in all spheres of development for CYP and is an important rehabilitation outcome (Bedell and Coster, 2008; Chien et al., 2014; Galvin et al., 2010). The introduction of the ICF has led to increased focus on participation as an outcome and the development of several outcome measures (Chien et al., 2014). This study aimed to explore the levels of participation in a sample of UK CYP-ABI at home, school and in the community after discharge from inpatient rehabilitation using a multi-centre cross-sectional survey. Whilst recruitment to this study via postal invitation was low, the online data collection method and survey was effective for those participants that completed it. Important knowledge has been gained with participants' voices being enabled to be heard and similar factors impacting participation identified, consistent with previous studies (Bedell and Dumas, 2004; Galvin et al., 2010; Wells et al., 2009). Participation in structured community activities and social, play and leisure activities rely on a high degree of skill socially, cognitively and physically and the ability to adapt quickly to changing situations and responses from others (Galvin et al, 2010). Social interaction is fundamental to child development and disruption at any stage of the lifespan can have implications for mental health, QoL, academic and career achievement (Anderson et al., 2013). Although relatively invisible, the impact of cognitive and communication impairments are common after ABI, impact heavily on participation and are a major source of stress and burden for CYP and families, as demonstrated in this small sample (Turkstra et al. 2015). Increased awareness of ongoing cognitive and communication 
difficulties is vital to ensure effective support and assistance for CYP and their families (Galvin et al., 2010; Turkstra et al., 2015).

The environmental factors component of the ICF represents external influences on function, physical, social and attitudinal (Ciccia and Threats, 2015). Family stress, lack of support/encouragement and services in the community were reported by parents as environmental factors impacting on participation. Parental stress and burden are known to be directly related to functional outcome after youth traumatic brain injury with sibling reaction/stress also playing an important role (Aitken et al., 2009; Ciccia and Threats, 2015). Whilst there are positive developments within wider society to address participation of people with disabilities, there are still many barriers to achieving full societal participation following childhood ABI (Brittain and Beacom, 2016). A family-centred ethos to long-term CYP-ABI rehabilitation is critical in recognising and addressing the impact on the whole family and the influence of family stress on the CYPs recovery (Aitken et al., 2009; Cole et al., 2009).

\section{Limitations:}

This study has provided novel insights pertaining to participation of CYP-ABI. Whilst we recognise that the findings are not generalizable, they do indicate that there may be outstanding needs and issues for CYP-ABI and their parents that require further exploration, support and intervention. However, this study does have a number of limitations that must be recognised relating to access to participants, and recruitment/survey responses.

Firstly, the CYP-ABI population were difficult to identify and access. Currently in the UK, there is no established CYP-ABI registry or national patient and public involvement (PPI) forum. Therefore, this study accessed potential participants via the CYP-ABI's local hospital through the clinical ABI services database. However, this approach was limited as it was dependent upon local hospitals maintaining the quality and completeness of these databases 
(such as up to date contact details). As such some potential participants may not have been invited due to changes in contact details.

Secondly, the postal invitation recruitment method proved unsuccessful as it yielded a very low response rate. Therefore, it must be recognised that the views/experiences identified in the findings of this study, may not transferable to the national heterogeneous cohort. Despite attempts to improve responses, with a protocol amendment for telephone prompts, this did not result in an increase in recruitment. Whilst other recruitment methods were explored when designing this study, such as telephone invitations or recruitment in clinics, postal invitations were deemed the least intrusive for families and feasible in light of the time and resources available.

Collectively, the design of the study was considered at length and a parent and child were involved in this process alongside feedback from other local service users. However, in relation to addressing these limitations in future research, more extensive and geographically wider PPI is required to establish effective approaches to recruit participants (Hunt et al., 2015), as well as strategies for optimising responses to surveys. The reality of typical $21^{\text {st }}$ century family life is busy balancing multiple demands, with this population having the added complexity of supporting a CYP-ABI; this may have affected the response rate (Aitken et al., 2009; Bailey et al., 2014; Thompson et al., 2015; Wharton, 2012). Therefore, a range of methods for reporting should also be offered (such as postal, telephone, face to face, or online) as this may accommodate the potentially diverse and changing demands that families have and enhance opportunities for research participation (Pulham et al, 2019).

\section{Conclusion}

This study aimed to explore levels of participation in CYP-ABI. Whilst the response rate was low, these findings, though not generalizable, are important and informative. Particularly the 
qualitative responses, have provided rich and novel insights into the phenomena. Participation is an important goal of long-term rehabilitation/support for CYP-ABI and clinicians should seek to address factors that affect it. In order to optimise participation for CYP-ABI throughout their lifespan, awareness needs to be raised. The challenges for researchers of engaging with, accessing and recruiting CYP and their parents for research should not be a prohibitive barrier to work in this field. As researchers we need to seek appropriate funding, increase preparatory dialogue with CYP-ABI and their parents to delimit such potential barriers in order to increase their involvement in research. Establishing a national network for CYP-ABI and their families should be considered to provide family peer support and support future research through PPI engagement. Further research aimed at comprehensively understanding acceptable and feasible research methods with this population is essential to ensure future research is effective in reaching and engaging CYP-ABI and their families. Additionally, international comparison is required to establish the generalisability/transferability of the phenomena. Whilst it is necessary to investigate participation levels with a larger population, it is apparent that engagement of CYP-ABI and their families in research itself must also be addressed.

\section{$\underline{\text { Acknowledgments: }}$}

\section{Declaration of interest:}

The authors report no conflict of interest. 


\section{$\underline{\text { References: }}$}

Adolfsson M, Malmqvist J, Pless M, Granlund M (2011) Identifying child function from an ICF-CY perspective: everyday life situations explored in measures of participation. Disability and Rehabilitation. 33:1230-1244.

Aitken ME, Mccarthy ML, Slomine BS, Ding R, Durbin DR, Jaffe KM, Paidas CN, Dorsch AM, Christensen JR, Mackenzie EJ, et al. (2009) Family burden after traumatic brain injury in children. Pediatrics. 123(1):199-206.

Anderson V, Beauchamp M, Yeates K, Crossley L, Hearps S, Catroppa C (2013) Social Competence at 6 Months Following Childhood Traumatic Brain Injury. Journal of the International Neuropsychological Society. 19:539-550.

Anderson V, Catroppa C, Dudgeon P, Morse S, Haritou F, Rosenfeld J (2006) Understanding predictors of functional recovery and outcome thirty-months following early childhood head injury. Neuropsychology. 20(1)42-57.

Anderson V, Godfrey C, Rosenfeld JV, Catroppa C. (2012) 10 years outcome from childhood traumatic brain injury. International Journal of Developmental Neuroscience. 30:217-224.

Andersson K, Bellon M, Walker R (2016) Parents' experiences of their child's return to school following acquired brain injury (ABI): A systematic review of qualitative studies. Brain Injury. 30(7):829-838.

Arain M, Campbell M, Cooper C, Lancaster G (2010) What is a pilot or feasibility study? A review of current practice and editorial policy. BMC Medical Research Methodology. 10(67):52.

Badge H, Hancock J, Waugh M-C (2009) Evaluating paediatric brain injury services in NSW. Child: care, health and development. 36(1):54-62.

Bailey S, Boddy K, Briscoe S, Morris C (2014) Involving disabled children and young people as partners in research: a systematic review. Child: Care, Health and Development. 41(4):505-514.

Bedell G (2011) The Child and Family Follow-up Survey (CFFS) - Administration and Scoring Guidelines. USA. Available at: http://sites.tufts.edu/garybedell/files/2012/ 07/CFFSAdministration-Scoring-Guidelines-9-24-111.pdf (Accessed 2016 Dec 12)

Bedell G, Coster W (2008) Measuring participation of school-aged children with traumatic brain injuries: considerations and approaches. Journal of Head Trauma Rehabilitation. 23(4):220-229.

Bedell G.M. and Dumas, HM (2004) Social participation of children and youth with acquired brain injuries discharged from inpatient rehabilitation: a follow-up study. Brain Injury. 18(1):65-82.

Bedell G, Khetani M, Cousins M, Coster W, Law M (2011) Parent perspectives to inform development of measures of children's participation and environment. Archives of Physical Medicine and Rehabilitation. 92:765-73.

Braun V and Clarke V (2006) Using thematic analysis in psychology. Qualitative Research in Psychology. 3:77-101

Brittain I, Beacom A (2016) Leveraging the London 2012 Paralympic Games: What Legacy for Disabled People. Journal of Sport and Social Issues. 40(6):499-521. 
Chien C-W, Rodger S, Copley J, Skorka K (2014) Comparative Content Review of Children's Participation Measures Using the International Classification of Functioning, Disability and Health-Children and Youth. Archives of Physical Medicine and Rehabilitation. 95:141.

Ciccia A, Threats T (2015) Role of contextual factors in the rehabilitation of adolescent survivors of traumatic brain injury: emerging concepts identified through modified narrative review. International Journal of Language and Communication Disorders. 50(4):436.

Cole W, Paulos S, Cole C, Tankard C (2009) A Review of Family Intervention Guidelines for Pediatric Acquired Brain Injuries. Developmental Disabilities Research Reviews. 15:159166.

Datta J, Petticrew M (2013) Challenges to evaluating complex interventions: a content analysis of published papers. BMC Public Health. 13:568.

De Kloet A, Gijzen R, Braga L, Meesters J, Schoones J, Vliet Vlieland T (2015)

Determinants of participation of youth with acquired brain injury: A systematic review. Brain Injury. 29(10):1135-1145.

Emanuel EJ, Wendler D and Grady C. (2000) What makes clinical research ethical? JAMA 2000 May 24-31:283(20):2701-11

Feary N and McKinlay A. (2018) Impact of mild traumatic brain injury understanding on intended help-seeking behaviour. Journal of Child Health Care. 1367493518799617

Fougeyrollas P, Lepage C, Boissière L, Deaudelin I, Doré L (2014) Assessment of social participation in three measurement times in children with traumatic brain injuries (TBI) based on parental perceptions. Open Journal of Therapy and Rehabilitation. 2:156-165.

Galvin, J., E. Froude, and McAleer, J (2010) Children's participation in home, school and community life after acquired brain injury. Australian Occupational Therapy Journal. 57:118-126.

Gordon A (2014) Functioning and disability after stroke in children: using the ICF-CY to classify health outcome and inform future clinical research priorities. Developmental Medicine \& Child Neurology. 56:434-444.

Gordon A, di Maggio A. (2012) Rehabilitation for Children After Acquired Brain Injury: Current and Emerging Approaches. Pediatric Neurology. 46:339-344.

Hunt A, Brown E, Coad J, Staniszewska S, Hacking S, Chesworth B, Chambers L. (2015) 'Why does it happen like this?' Consulting with users and providers prior to an evaluation of services for children with life limiting conditions and their families. Journal of Child Health Care. 19(3):320-333

Kirk S, Fallon D, Fraser C, Robinson G, Vassallo G (2015) Supporting parents following childhood traumatic brain injury: a qualitative study to examine information and emotional support needs across key care transitions. Child: Care Health and Development. 41(2):303313.

Law M, Anaby D, Dematteo C, Hanna S (2011) Participation patterns of children with acquired brain injury. Brain Injury. 25(6):587-595.

Limond J, Dorris L, McMillan T (2009) Quality of life in children with acquired brain injury: Parent perspectives 1-5 years after injury. Brain Injury. 23(7-8):617-622. 
Maguire M and Delahunt B. (2017) Doing a Thematic Analysis: A Practical, Step-by-Step Guide for Learning and Teaching Scholars, All Ireland Journal of Teaching and Learning in Higher Education, 12(3):3351-33514

Manning JC, Hemingway P and Redsell SA. (2017) Stories of survival: Children's narratives of psychosocial well-being following paediatric critical illness or injury. Journal of Child Health Care. 21(3):236-252

McConachie H, Colver A, Forsyth R, Jarvis S, Parkinson KN (2006) Participation of disabled children: how should it be characterised and measured. Disability and Rehabilitation. 28(18):1157-1164.

McDougall J, Bedell G, Wright V (2013) The youth report version of the Child and Adolescent Scale of Participation (CASP): assessment of psychometric properties and comparison with parent report. Child: Care, Health and Development. 39(4):512-522.

NHS England (2013) 2013/2014 NHS Standard Contract for Paediatric Neurosciences: Neurorehabilitation Section B Part 1 - Service Specifications. London: NHS England. Available at: https://www.england.nhs.uk/wp-content/uploads/2013/06/e09-paedineurorehabilitation.pdf (Accessed 2016 Nov 14)

Popernack M, Gray N, Reuter-Rice K (2015) Moderate-to-Severe Traumatic Brain Injury in Children: Complications and Rehabilitation Strategies. Journal of Pediatric Health Care. 29(3):1-7.

Pulham, R.A., Wray, J., Feinstein, Y., Brown, K., Pierce, C., Nadel, S., Pathan, N., Garralda, E. and Ramnarayan, P., 2019. Feasibility and Acceptability of Methods to Collect Follow-Up Information From Parents 12 Months After Their Child's Emergency Admission to Pediatric Intensive Care. Pediatric Critical Care Medicine, 20(4), pp.e199-e207.

Royal College of Paediatrics and Child Health (2017) Stroke in Childhood: Clinical guideline for diagnosis, management and rehabilitation. London. RCPCH Available at:

https://www.rcpch.ac.uk/sites/default/files/2018-07/2017_stroke_in_childhood_guideline_final_3.6.pdf(Accessed 2017 Jun 30)

Thompson H, Frederico N, Smith S, Chowdhury M, Dicks P, Preston J, Thompson C (2015) iCan: Providing a Voice for Children and Families in Pediatric Research. Therapeutic Innovation \& Regulatory Science. 49(5):673-679.

Thompson M, Elliott C, Willis C, Ward R, Falkmer M, Falkmer T, Gubbay A, Girdler S (2016) Can, Want and Try: Parent's viewpoints regarding the participation of their child with an acquired brain injury. PLoS ONE. 11(7):e0157951.

Turkstra L, Politis L, Forsyth R (2015) Cognitive-communication disorders in children with traumatic brain injury. Developmental Medicine and Child Neurology. 57:217-222.

Wells R, Minnes P, Phillips M (2009) Predicting social and functional outcomes for individuals sustaining paediatric traumatic brain injury. Developmental Neurorehabilitation. 12(1):12-23.

Wharton A (2012) Work and Family in the 21st Century: Four Research Domains. Sociology Compass. 6(3):219-235

World Health Organisation (2002) Towards a Common Language for Functioning, Disability and Health - ICF. Geneva. World Health Organisation. Available at:

http://www.who.int/classifications/icf/en/ (Accessed 2016 Dec 4) 
Demographics of the CYP participants

\begin{tabular}{llllll}
\hline Demographic Information & n (\%) & Min. & Max. & Median & $\begin{array}{l}\text { Standard } \\
\text { Deviation }\end{array}$ \\
\hline $\begin{array}{l}\text { Age (years) } \\
\text { Gender }\end{array}$ & & 6 & 15 & 12 & 4.09 \\
Male & $1(20)$ & -- & -- & -- & -- \\
Female & $3(60)$ & -- & -- & -- & -- \\
Unspecified & $1(20)$ & -- & -- & -- & -- \\
Diagnosis & & & & - & -- \\
Trauma & $4(80)$ & -- & -- & -- & - \\
Infection & $1(20)$ & -- & -- & -- & 8.3 \\
Time since injury (months) & -- & 19 & 38 & 24.93 & 7.61 \\
Time since discharge (months) & -- & 17 & 34 & 24.77 & 55.4 \\
Length of Stay (days) & -- & 5 & 118 & 52 & \\
Admitting Hospital & & & & - & -- \\
Centre 1 & $3(60)$ & -- & -- & -- & -- \\
Centre 2 & 0 & -- & -- & -- & -- \\
Centre 3 & $1(20)$ & -- & -- & -- & -- \\
Centre 4 & $1(20)$ & -- & -- & -- & \\
Mainstream School & $5(100)$ & & & - & -- \\
Primary & $2(40)$ & -- & -- & -- & -- \\
Secondary & $3(60)$ & -- & -- & -- & \\
\hline
\end{tabular}


CASP (parents) and CASP-Y (CYP) Scores

\begin{tabular}{|c|c|c|c|c|c|c|c|c|c|c|c|c|}
\hline & \multicolumn{6}{|c|}{ CASP Score- parent reported (n) } & \multicolumn{6}{|c|}{ CASP-Y Score - CYP reported (n) } \\
\hline & $\begin{array}{l}\text { Age } \\
\text { expected }\end{array}$ & $\begin{array}{l}\text { Somewhat } \\
\text { limited }\end{array}$ & $\begin{array}{l}\text { Very } \\
\text { limited }\end{array}$ & Unable & $\mathrm{N} / \mathrm{A}$ & $\begin{array}{l}\text { Total } \\
\text { affected }\end{array}$ & $\begin{array}{l}\text { Age } \\
\text { expected }\end{array}$ & $\begin{array}{l}\text { Somewhat } \\
\text { limited }\end{array}$ & $\begin{array}{l}\text { Very } \\
\text { limited }\end{array}$ & Unable & N/A & $\begin{array}{l}\text { Total } \\
\text { affected }\end{array}$ \\
\hline \multicolumn{13}{|l|}{ Home Participation } \\
\hline Social, play, leisure with family & 3 & 2 & -- & -- & -- & 2 & 2 & -- & 1 & -- & -- & 1 \\
\hline Social, play, leisure with friends & 2 & 3 & -- & -- & -- & 3 & 1 & 1 & 1 & -- & -- & 2 \\
\hline Family chores at home & 3 & 2 & -- & -- & -- & 2 & 1 & 2 & -- & -- & -- & 2 \\
\hline Self-care activities & 3 & 2 & -- & -- & -- & 2 & 2 & 1 & -- & -- & -- & 1 \\
\hline Moving in and around home & 4 & 1 & -- & -- & -- & 1 & 3 & -- & -- & -- & -- & 0 \\
\hline Communication & 3 & 1 & 1 & -- & -- & 2 & 2 & 1 & -- & -- & -- & 1 \\
\hline \multicolumn{13}{|l|}{ Community Participation } \\
\hline Social, play, leisure with friends & 2 & 1 & 1 & 1 & -- & 3 & 1 & 1 & 1 & -- & -- & 2 \\
\hline Structured events/activities & 1 & 2 & 2 & -- & -- & 4 & 1 & -- & 1 & -- & 1 & 1 \\
\hline Moving around neighbourhood & 2 & 1 & 2 & -- & -- & 3 & 2 & -- & 1 & -- & -- & 1 \\
\hline Communication & 3 & -- & 2 & -- & -- & 2 & 1 & -- & 2 & -- & -- & 2 \\
\hline \multicolumn{13}{|l|}{ School Participation } \\
\hline Educational activities & 1 & 4 & -- & -- & -- & 4 & 2 & -- & 1 & -- & -- & 1 \\
\hline Social, play, recreation with peers & 2 & 3 & -- & -- & -- & 3 & 1 & 1 & 1 & -- & -- & 2 \\
\hline Moving around & 3 & 2 & -- & -- & -- & 2 & 8 & 1 & -- & -- & -- & 1 \\
\hline Using educational materials & 5 & -- & -- & -- & -- & 0 & 3 & -- & -- & -- & -- & 0 \\
\hline Communication & 2 & 2 & 1 & -- & -- & 3 & 2 & -- & 1 & -- & -- & 1 \\
\hline \multicolumn{13}{|c|}{ Home and community living activities } \\
\hline Household activities & 1 & 3 & -- & -- & 1 & 3 & 2 & -- & 1 & -- & -- & 1 \\
\hline Shopping and managing money & 2 & 2 & -- & -- & 1 & 2 & 2 & -- & 1 & -- & -- & 1 \\
\hline Managing daily schedule & 2 & 2 & -- & -- & 1 & 2 & 2 & -- & 1 & -- & -- & 1 \\
\hline Using transport & 1 & 1 & 1 & 1 & 1 & 3 & 1 & -- & 1 & -- & 1 & 1 \\
\hline Work activities/responsibilities & 1 & 2 & -- & -- & 2 & 2 & 1 & -- & 1 & -- & 1 & 1 \\
\hline
\end{tabular}


